\title{
Microparticle Impacts Observed on the Hubble Space Telescope Solar Array
}

\author{
Lucinda Berthoud \\ European Space Agency, European Space Research and Technology \\ Centre, 2200 AG Noordwijk, The Netherlands. \\ Klaus Paul \\ Fachgebiet Raumfahrttechnik, TU München, 80333 München, Germany
}

\begin{abstract}
The recent recovery of the Hubble Space Telescope (HST) Solar-Array-1 offers a unique opportunity to improve our knowledge of the low Earth orbit (LEO) particle environment. The data from HST surfaces is particularly interesting for the meteoroid and debris community, as the Telescope was in orbit at an altitude of approximately $614 \mathrm{~km}$ and there has been no data from such a high orbit before.
\end{abstract}

\section{Introduction}

The Hubble Space Telescope was launched on 24 April 1990 into a $614 \mathrm{~km}$ low Earth orbit (LEO). Its two roll-out flexible solar arrays were deployed on 25 April 1990. During the Hubble repair mission one of the two solar arrays was retracted (on 5 December 1993) and brought back to Earth, whilst the other was jettisoned. One of the areas of post-flight investigation is the effect of particle impact on the solar arrays. The solar cells and the thermal blankets that were wrapped around various structures provide interesting surfaces to examine. This work is consequently divided into two sections: the first describing investigations of impacts on thermal blankets carried out at ESTEC in the Materials and Processes Division, and the second describing results from impacts on solar cells at ESTEC and at the Technical University of Munich, Fachgebiet Raumfahrttechnik.

\section{HST thermal blanket investigation}

The IST thermal blankets were wrapped around the boom between the Primary and Secondary Deployment Mechanisms. The wrapped position of the blankets meant that all sides were apparentiy exposed to microparticle impact. The three samples were $18.5 \times 37.1 \mathrm{~cm}$ in size $\left(685 \mathrm{~cm}^{2}\right)$. The blankets have 19 layers. The top layer is a protective thermal tape consisting of Teflon $(125 \mu \mathrm{m}$ thick), a vapour-deposited layer of silver (1300 A), Inconel $(300 \AA)$ and then a layer of 960 acrylic adhesive $(30-40 \mu \mathrm{m})$ to glue the tape to the next layer of PTFEimpregnated glass fibre cloth. There are then 16 layers of double aluminized 


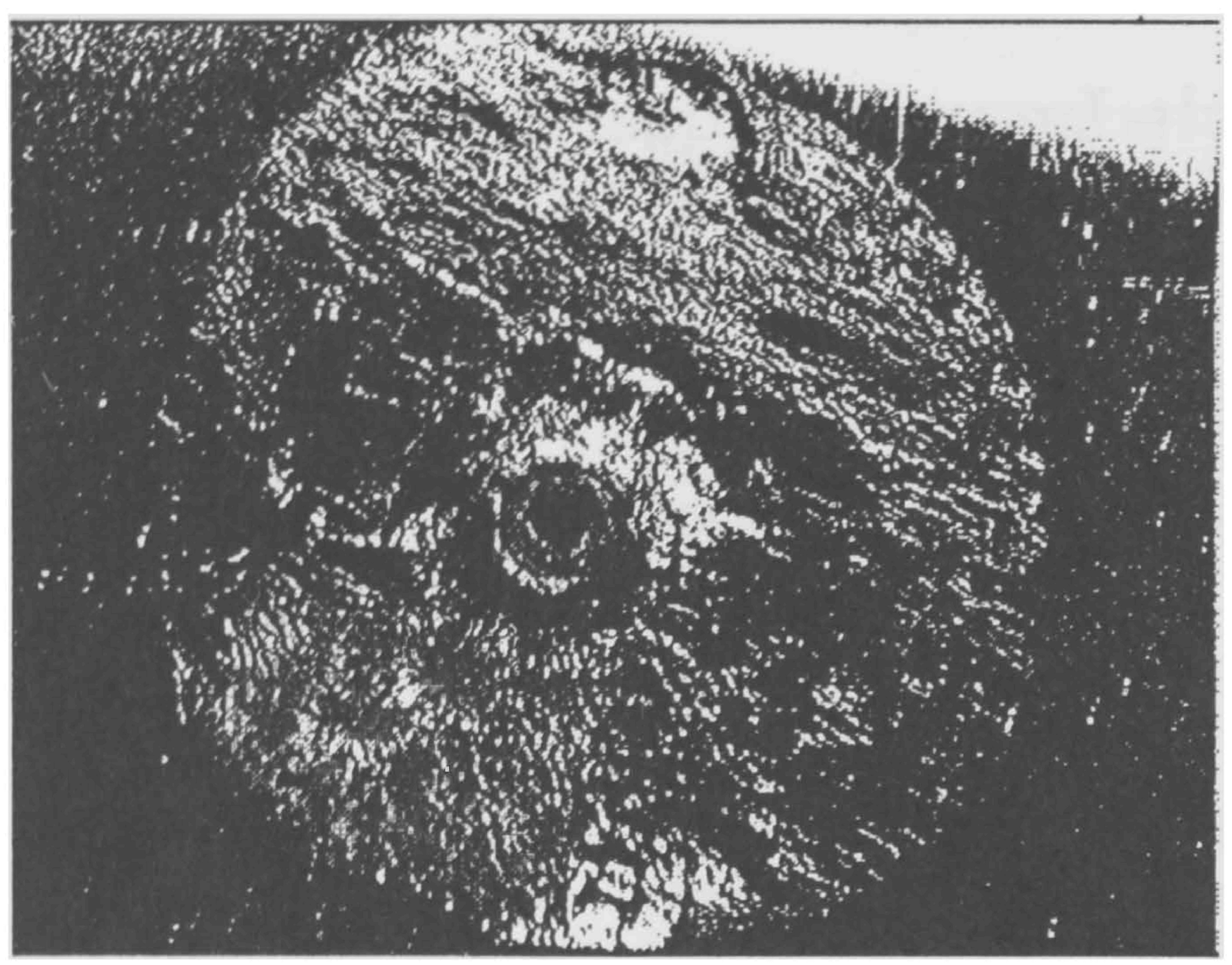

Figure 1. Microscope image to show area of delamination (diameter $5 \mathrm{~mm}$ ) and small penetration hole in teflon (diameter $464 \mu \mathrm{m}$ ) layer of blanket B-17

Kapton with dacron net between each layer to inhibit interlayer heat transfer by conduction.

The blankets affected the impact of microparticles by slowing them down through each layer. Not a single particle penetrated through the entire blanket structure. On blanket $\mathrm{A}$, ten impacts were found. On blanket $\mathrm{B}, 16$ impacts, and on blanket C, 14 impacts were found. The impacts ranged in size from 60 to 680 microns (crater diameter) with maximum damage diameter of up to 7 $\mathrm{mm}$. The morphologies of the impact features appear to vary with size. For impacts with diameter under about $150 \mu \mathrm{m}$, a crater is formed in the Teflon. For impacts larger than $150 \mu \mathrm{m}$, the particle has usually penetrated the first FEP layer (see figure 1). In almost all cases, damage areas with diameters from 3 to 20 times the hole diameter were formed in the $\mathrm{Ag} / \mathrm{Inconel}$. In at least five of the impacts, the particle penetrated several layers. In general the hole in the glass fibre tends to be slightly larger than that in the Teflon. The holes or impressions in the layers underneath decrease in diameter.

\section{Solar cell investigation}

In this work, we have adopted the crater measurement system used for microimpacts on lunar rocks (Hörz et al. 1971, and Vedder and Mandeville, 1974): a central bowl-shaped pit (described by pit diameter $D_{P i t}$ ) is surrounded by a halo of shattered glass, then by a depression created by the ejection of spall from an area dominated by concentric cracks $\left(D_{C o}\right)$. The cells examined here were selected from two (D and $E$ ) of the five panels which make up each solar array wing. Table 1 resumes the results of systematic scanning of the cells by optical and scanning electron microscopes (SEM): 
Table 1. Details of cell scanning.

\begin{tabular}{lrlrrr} 
Type of scanning & No. cells & Magnification & $\begin{array}{c}\text { No. impacts } \\
\text { counted }\end{array}$ & $\begin{array}{c}\text { Smallest } \\
D_{C o}[\mu \mathrm{m}]\end{array}$ \\
\hline Optical & & & $20 \times$ & 13 & 32 \\
SEM & 10 & & $50 \times$ & 151 & 9 \\
& 58 & $\left(20 \mathrm{~cm}^{2}\right)$ & $500 \times$ & 33 & 2 \\
& 7 & $\left(8.5 \mathrm{~cm}^{2}\right)$ & $200 \times$ & 22 & 2
\end{tabular}

\section{Flux comparisons}

The ESABASE meteoroid and debris tool (Borde, 1991) employs Grün's meteoroid model (Grün, 1985) and Kessler's debris model (described in Anderson, 1990). The parameters chosen for the model and the results in detail are described elsewhere (Drolshagen, 1995). To compare the flux results predicted by the ESABASE model to the observed flux, we have to convert the particle diameters produced by the models to crater diameters. This is usually done with equations derived empirically from laboratory impact simulations. In this volume, (Paul and Berthoud, 1995) describe several new empirical equations adapted to fit both $\mathrm{n} \in \mathrm{w}$ and old laboratory data for impacts on glass. All units are cgs.

$$
D_{P i t}=1.12 \cdot 10^{-4} \rho_{t}^{-0.5} \rho_{p}^{0.743} \cdot d^{1.077} v^{0.726} \cos ^{0.150} \Theta
$$

$$
\begin{array}{llll}
d & \text { particle diameter }[\mathrm{cm}] & D_{P i t} & \text { pit diameter }[\mathrm{cm}] \\
\rho_{p} & \text { density of projectile }\left[\mathrm{g} / \mathrm{cm}^{3}\right] & \rho_{t} & \text { density of target }\left[\mathrm{g} / \mathrm{cm}^{3}\right] \\
V & \text { normal comp. of vel. }[\mathrm{cm} / \mathrm{s}] & \Theta & \text { angle of incidence from vert. }\left[^{\circ}\right]
\end{array}
$$

Equation 1 was used to convert $d$ to $D_{P i t}$ for both debris and meteoroids fluxes calculated by the model. There are certain assumptions that have to be made about the environment: for debris we used $V=11 \mathrm{~km} / \mathrm{s}, \rho_{p}=4 \mathrm{~g} / \mathrm{cm}^{3}$ and for micrometeoroids $V=17 \mathrm{~km} / \mathrm{s}$ with $\rho_{p}=1 \mathrm{~g} / \mathrm{cm}^{3}$ and an average $\Theta$ of $45^{\circ}$ was assumed. The results are shown in Figure 2 below, where the HST observed and modelled fluxes are compared with the EURECA observed flux (data from ESTEC, 1994).

The modelled HST flux seems to approximate the observed flux relatively well down to pit diameters of $10 \mu \mathrm{m}$. Below this, the model diverges from the observed data. This tendency has been noticed before in similar data from NASA's Long Duration Exposure Facility (Mandeville and Berthoud, 1993). It has been explained by inaccuracies in the debris model, which appears to be overestimating the flux in the micron regime. Although there is not much overlap in the EURECA and HST data, it seems that for pit diameters over $100 \mu \mathrm{m}$, the two fluxes are consistent. For smaller particles the EURECA data falls off. This may be because of a roll-off due to reaching the limit of resolution, or to additional secondary impacts on HST surfaces (many small oblique craters were observed indicating this may be a possibility). 


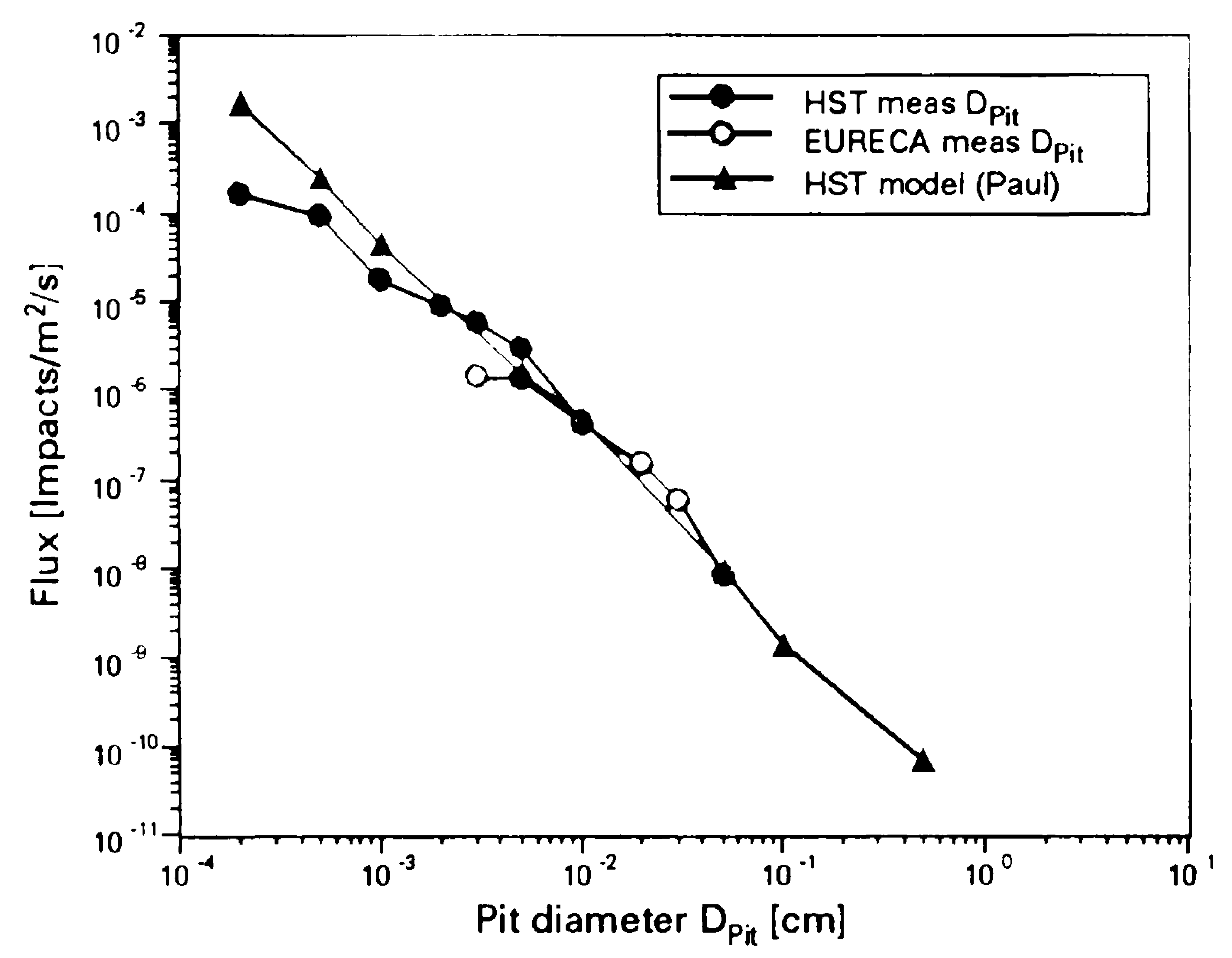

Figure 2. Comparison of HST observed (HST meas $\mathrm{D}_{\text {pit }}$ ) and modelled (HST model (Paul)) fluxes with EURECA observed flux (EURECA meas $\left.D_{\text {pit }}\right)$.

\section{Conclusions}

An analysis of micro-impacts on three HST thermal blankets and on 68 HST solar cells has been performed. The sizes and morphologies of these craters and holes has been investigated. Micrometeoroids and space debris only penetrated the top 3 layers of the thermal blankets, although significant delamination was caused. HST fluxes deduced from the blankets and cells compare well with predictions made using modelled distributions. However, it did appear that the Kessler debris model is overestimating flux for micron-sized particles. There was also some evidence of secondary impacting on HST surfaces.

\section{References}

Anderson B.J.-ed. 1990, NASA SP-30425.

Berthoud L. 1994, ESA SP-368.

Borde J. 1991, ESA contract report S413/RT/11.91.

Drolshagen G. 1995, Proc. HST Solar Array Workshop, ESTEC, The Netherlands, 30-31 May 1995.

ESTEC, 1994, ESA contract report. 10522/93/NL/JG, September 1994.

Grün E., Zook H. èt al. 1985, Icarus 62, pp. 244-272.

Hörz,F.. Hartung J.B. and Gault D.E. 1971, JGR, Vol. 76, 23, 5570-5798.

Mandeville J.C. and Berthoud L. 1993, ESA SD-01.

Paul K. and Berthoud L. this volume.

Vedder J.F. and Mandeville J.C. 1974, JGR, Vol. 79, No. 23, pp 3247-3256. 